\title{
Los rezagos de la Politica Social
}

The Lags of Social Policy

\section{David Ibarra*}

* Doctor Honoris Causa por

la UnAm, ex secretario de

Hacienda y exdirector de

CEPAL-México.

«dibarra@prodigy.net.mx»

Journal of Economic Literature (JEL):

J3, J4, I31, D61, E24

Palabras clave:

Mercado de Trabajo

Distribución del Ingreso

Salarios

Desempleo

Keywords:

Labor Market

Income Distribution

Wages

Unemployment

\section{Resumen}

Los fenómenos de la concentración del ingreso y la riqueza, de la erosión de los mercados de trabajo, se traducen en desprotección de las poblaciones. Los pactos sociales han quedado rotos, los salarios retroceden y los excedentes de la mano de obra persisten, se expresan en desempleo o informalidad, impidiendo que la política social brinde seguridad indispensable a las sociedades y, al hacerlo, legitime las políticas de los gobiernos. A escala global y de los países comienza a ser tiempo de completar o sustituir las viejas funciones armonizadoras de los mercados de trabajo entre economía y democracia. Y, al propio tiempo, de hacer que los gobiernos recobren la capacidad de defender los intereses generales, despegándose de la defensa de las elites. Se presentan algunas ideas de cambio de políticas, aunque todavía se esté lejos de la formulación de nuevos paradigmas sobre el orden socio-político universal y del interno de los países. Con todo ya va siendo hora de comenzar a plantear alternativas frente a desigualdades en ascenso y una crisis mundial casi interminable.

\section{Abstract}

Income and wealth concentration and labor markets obsolescence translate themselves in social insecurity for the populations. The main social covenants are broken, labor's GNP share and salaries are retreating, while labor surpluses explain chronic unemployment in some countries and informal occupations in others, both of which deprive society of adequate protection and deteriorate gubernamental legitimacy. At the global and national levels, it is time to revise or replace the impaired functions of the labor markets in mediating between market and democracy. And perhaps it is also time for the governments to fight for the collective interests instead for those of the economic elite. In spite of the presentation and discussion of some partial changes in economic and social policies, the prevailing world ideology is ill prepared to assimilate such changes and formulate a different world order. Anyhow we have to think in ways to correct the prevailing social inequalities, as well as, an unending world crisis. 


\section{Introducción}

Afirmar que la política social de cualquier país es un producto histórico ya es un lugar común. Lo que no siempre se señala es la brecha entre los grandes o los pequeños ajustes acumulativos derivados de circunstancias cambiantes de la realidad y los contenidos usualmente rezagados de las protecciones ofrecidas a la población.

La política social satisface funciones importantísimas, insustituibles, que van desde la legitimación de los gobiernos hasta brindar seguridad a la población, sobre todo a la de menores recursos. Esas políticas tampoco tienen como único objetivo aliviar la pobreza, sino reducir el impacto de las eventualidades sociales, prestar servicios colectivos, proveer de bienes públicos a los ciudadanos. Se trata de evitar o atenuar riesgos y, luego, compensarlos cuando aparecen conforme a estándares convenidos, al tiempo que se sostienen cánones también aceptados, aunque siempre en disputa, de reparto de riqueza e ingreso.

Las políticas sociales, sobre todo cuando ganan en estabilidad, resultan inevitablemente de acuerdos políticos. Gobiernos y elites convienen o imponen los denominadores comunes, frecuentemente mínimos, de protección social que han de brindarse a las poblaciones. Esa política desempeña funciones que resguardan desde la legitimidad de los gobiernos y la paz ciudadana, hasta la seguridad de los diferentes estratos sociales. Puestos en otros términos, persiguen objetivos múltiples que no se reducen, ni pueden reducirse a aliviar la pobreza, a corregir o compensar riesgos sociales -enfermedad, vejez, desempleo, insuficiencia de ingresos- conforme a normas regulatorias conocidas. Vista así la política social, no es reducible -como suele hacerse con los salarios - , a un costo de producción que resta competitividad internacional a las empresas. ${ }^{1}$

Históricamente, la conmoción creada por la Revolución Industrial de los siglos XVIII y xIX y a la que se añaden después los apremios múltiples de la Gran Depresión de los Años Treinta, de la Guerra Fría, de la competencia con el mundo soviético, llevaron a un enorme ajuste social, a erigir los estados benefactores, aceptar con el keynesianismo el empleo pleno como la responsabilidad de los gobiernos y al mercado de trabajo, como la institución vertebral de la cohesión social. El ajuste fundamental consistió en abrir las puertas de la seguridad social y de los beneficios públicos o privados a la mano de obra a condición de su inserción obligada en el mercado de

1 Dadas las enormes diferencias salariales y de excedentes de mano de obra entre los países, el enfoque de la protección social como rémora a la competitividad, salvo que excepcionalmente sea compensada por diferenciales también enormes de la productividad comparativa, condenan esa protección a estándares mínimos internacionales ("race to the bottom"). Se trata de un dilema añejo a la globalización que en parte explica el desplazamiento de la inversión-producción a las zonas de mano de obra e insumos baratos (Véanse, A. Amsden (2001), The Rise of the Rest: Challenges to the West from Late Industrializing Economies, Oxford University Press, N. York; M. Connelly y P. Kennedy (1994) "Must it be the Rest Against the West?", Atlantic Monthly, Vol. 274, núm. 6, pp. 61-84; Noah, T. (2012), The Great Divergence, Boomsbury Press, N. York; D. Ibarra (2006), La Reconfiguración Económica Internacional, unAm. Facultad de Economía, México). 
trabajo con el compromiso de aceptar la disciplina empresarial del sistema económico capitalista. ${ }^{2}$

Ese compromiso se correspondía punto por punto con la situación socioeconómica que prevalecía hasta bien avanzado el siglo pasado y con las construcciones paradigmáticas de las políticas de la época. A nivel general, los gobiernos, a la par de tener amplia autonomía económica, se responsabilizaban del empleo, del crecimiento y de la cohesión distributiva de la sociedad. El manejo de los negocios quedaba en manos de administradores y consejeros que buscaban primordialmente el crecimiento y la capitalización de las empresas, mientras bancos e instituciones financieras cumplían la función subordinada de facilitar el financiamiento de negocios, gobiernos y familias. La concentración masiva de los trabajadores en fábricas y centros productivos, facilitaba el sindicalismo, la negociación colectiva, la vigencia de los estados benefactores y la generalización homogénea de las condiciones de trabajo en los ámbitos nacionales. Eso mismo, apuntalaba la división familiar de tareas: con las mujeres a cargo de los hogares, alejadas del mercado de trabajo y los varones, como los proveedores del sustento familiar. Las finanzas públicas del Primer Mundo se alimentaban principalmente con impuestos progresivos directos que se consideraban instrumentos de la igualdad social más que de rémora a la competitividad de las empresas. Las pensiones por envejecimiento demográfico todavía no presionaban a los presupuestos públicos ni a las finanzas empresariales; en tanto que la rápida incorporación de mano de obra joven, alimentada por las migraciones y la maduración demográfica, contribuía al financiamiento de los estados de bienestar y al pago de jubilaciones.

Todo ese edificio de realidades, normas, instituciones, planteamientos paradigmáticos, comienza a desmoronarse con las transformaciones de orden internacional e interno de los países que había subsistido hasta el último cuarto del siglo pasado. Una combinación de acontecimientos socava esa construcción y singularmente a los mercados de trabajo como mecanismo afianzador de los pactos sociales. Aquí se suman transformaciones del orden internacional y del orden interno de los países, en sus estructuras demográficas y tecnológicas en la división internacional de la producción y las finanzas, tanto como en la selección de las grandes prelaciones socioeconómicas y los estilos de encarar las fluctuaciones cíclicas o las crisis conforme a paradigmas que se van haciendo globales. Esa acumulación de mudanzas estructurales ha devenido en crisis económicas y crisis políticas subyacentes que han impedido a la protección social transformarse de manera correlativa e implantar

2 Véanse, S. Webb y B. Webb (1910), English Local Government: English Poor Law History, Longmans, Green, Londres; K. Polanyi (1944), The Great Transformation, Rinehart, Nueva York; R. Titmuss (1963), Essays on "The Welfare State", Allen and Unwin, Londres; E. Evans, (1978), Social Policy 1830-1914, Individualism, Collectivism and the Origins of the Welfare State, Routledge and Kegal, Londres; H. Ullman, (1981), German Industry and Bismarck's Social System, Croom Helm, Londres; Fraser (1981), The English Poor Law and the Origins of the British Welfare State; G. EspingAndersen (1985), Politics against Markets, Princeton University Press, Princeton; P. Swenson, (2002), Capitalism against Markets: The Making of Labor Markets and Welfare States in the United States and Sweden, Oxford University Press, Oxford; D. Ibarra (2007) "Limitantes a los servicios nacionales de salud" en Derechos Humanos y Realidades Sociales, unam, Facultad de Economía, México. 
innovaciones que la saquen de la inoperancia, que le permitan recobrar la jerarquía perdida. En tal sentido, habría que suplementar y quizá hasta sustituir las funciones tradicionales de los mercados de trabajo y comenzar a construir las instituciones de la protección social del futuro.

Valga entonces comenzar, señalando los factores erosionantes de los cometidos de las políticas sociales.

\section{El mercado de trabajo}

Los síntomas de la obsolescencia de los mercados de trabajo son ya inocultables, lo mismo en términos políticos que económicos. La alta movilidad internacional del capital junto con la globalización oligopolística de las cadenas productivas, el offshoring y el outsourcing y el desplazamiento de la inversión a los países de costos bajos de insumos y mano de obra, han restado influencia a las agrupaciones obreras nacionales, debilitado la membresía sindical, la negociación colectiva, la defensa de la ocupación y de los salarios. La migración de las prelaciones económicas fundamentales del pleno empleo y el crecimiento, a la búsqueda de la competitividad internacional, pone de manifiesto la hondura del cambio ideológico y el abatimiento consiguiente de la influencia política de los trabajadores de cada país y del mundo. ${ }^{3}$

Los fenómenos descritos, tienen distintas expresiones entre las que destaca la concentración casi universal del ingreso y de la distribución de las ganancias de la productividad. ${ }^{4}$ Por eso, en las zonas industrializadas el desempleo parece hacerse endémico, de larga duración, desde antes de la crisis de 2008 y afectar especialmente a la población joven y a las mujeres. En los países emergentes o en desarrollo se experimentan fenómenos demográficos contrastantes. En algunos, China por ejemplo, el subempleo se ha contraído sustancialmente y, con ello, la difusión numérica de pobreza. Pero otras regiones, resultan dañadas con la explosión del trabajo informal y el alejamiento distributivo entre los estratos de bajo y alto ingreso.

En el año 2000 el desempleo en el mundo alcanzaba a 176 millones de personas, esto es, más de $5 \%$ de la población activa. Ya para 2013 había rebasado más de 200 millones $(6 \%)$ y, según proyecciones, llegará a más de $8 \%$ de la propia población activa entre 2016 y 2018. El panorama del desempleo juvenil (15 a 24 años) es todavía peor. En 2013 se estima en 13\% y el de Europa en 18\%, mientras siguen ascendiendo

3 El rezago en la observancia de los derechos laborales como parte intrínseca de los derechos humanos, es una constante que debiera procurar revertirse en el mundo globalizado. Según el "Global Rights Index" de la "International Trade Union Confederation (ITUC) con 176 millones de afiliados, de los 139 países analizados, hay 87 que no reconocen el derecho de huelga, 53 que despiden empleados para rehusar negociaciones laborales y 35 que han encarcelado trabajadores por demandar derechos.

4 Véanse, T. Piketty y E. Saez (2003) "Income Inequaliy in the United States", Quarterly Journal of Economics, 118, núm. 1, pp. 1-39; T. Piketty (2014), Capital in the Twenty First Century, Harvard University; J. Stiglitz (2012), The Price of Inequality, WW. Hampton, N. York; T. Noah (2012), The Great Divergence, Bloomsburg Press, N. York; D. Zalewski y C. Whale (2010) "Financialization and Economic Inequality", Journal of Economic Issues, núm. 44 (3), pp. 757777; K. Pickett y R. Wilkinson (2009), The Spirit Level, Allen Lane, Inglaterra. 
los grupos de jóvenes que ni estudian ni trabajan. Como es natural, la desocupación femenina excede a la masculina (6.4\% y $5.8 \%$ respectivamente en 2013$)$. El desempleo, acompañado de precarización de las condiciones de trabajo (empleo temporal, de tiempo parcial, de poca calidad, con bajos salarios) o del abandono por desaliento de ese mercado, es peculiarmente intenso en los países industrializados y en la Unión Europea. Ahí el desempleo total (2013), se estima en 8.7\%, sólo inferior al de Medio Oriente y el Norte de Africa. 5

A mayor abundamiento, en un número creciente de países, el envejecimiento de la población acrecienta los costos de la seguridad social y del sostenimiento de las pensiones, en momentos en que la crisis económica hace tambalear las finanzas públicas de buena parte de las economías y se afianza el paradigma de la consolidación fiscal.

Otro fenómeno a notar es el desplome del empleo industrial en el Primer Mundo que, con el agrícola, acentúa el desplazamiento de las ocupaciones hacia los servicios con frecuente precarización de las ocupaciones y en desmedro de las organizaciones sindicales. En dichas zonas la participación de la ocupación fabril ha caído del 27 a $22 \%$ del total entre 2000 y 2013, compensada globalmente por su ascenso de Asia Sudoriental, mientras la de América Latina se debilita o estanca. ${ }^{6}$

Como se dijo, en muchos de los países en desarrollo, la erosión del mercado de trabajo, se expresa de manera diferente. En muchos se caracteriza por recuperación económica o desarrollo sin empleo. Hay más y más ocupaciones encerradas en la informalidad con acceso limitadísimo a la protección social. En más de un sentido, el fenómeno de la informalidad está emparentado con la pobreza, la desigualdad, ${ }^{7}$ el rezago educativo, pero refleja sobre todo la incapacidad de los sectores modernos de las economías para ensanchar la demanda de trabajadores y distribuir equitativamente las ganancias de la productividad. Entre 1991 y 2011, la población mundial pobre - ingresos hasta cuatro dólares diarios-, apenas decreció a $0.1 \%$ anual. En contraste las clases medias y los estratos mejor situados vieron acrecentar sus ingresos al ritmo de 5 a $6 \%$ anual, causando graves disparidades distributivas. 8

5 Véanse, ILO (varios números), World of Work Report, Ginebra; ILO (2012), Eurozone Job Crisis, Ginebra; ILO (2012), Statistical Update in the Internal Economy, Ginebra; CEPAL (varios números), Panorama Social de América Latina; R. Torres (2010), "Incomplete Crisis Reponses", International Labour Review, Vol. 149, núm. 2, pp. 127-137. Sin embargo, la Europa del Norte parece salir mejor librada de los serios problemas generales de desempleo característico de la década de los noventa y de la crisis actual de compararse con los Estados Unidos. En Francia, la probabilidad de empleo de adultos (25 a 55 años) es alta y mayor la movilidad social al igual que en países con amplios estados benefactores, como Suecia, Holanda, Dinamarca o Alemania. Desde luego, el desempleo juvenil es mayor al norteamericano, pero también son mayores las becas estudiantiles menores las colegiaturas.

6 Véase, ILo (2014), Global Employment Trends, Ginebra.

7 En América Latina 40\% de la población de menores ingresos apenas dispone de 15\% del producto y 4 de cada 10 trabajadores carece de acceso a la seguridad social.

8 Véase, ILO (varios números), Global Employment Trends, Ginebra; ILO (2013), Beyond Macroeconomic Stability, Ginebra. 
Cabe reiterar que en América Latina y otros lugares 9 el fenómeno de la informalidad cobra fuerza y agrava lo que se conocía como subempleo en actividades marginales de baja productividad. En muchas latitudes la parálisis de la modernización económica se hace permanente, dando lugar a la multiplicación de mercados fallidos de trabajo. En el año 2000, la informalidad cubría más de $75 \%$ de la ocupación asiática, más de $55 \%$ en Africa, más de 50\% en América Latina. Hoy en día, pese a avances significativos localizados en algunas regiones (China, Taiwán, Corea) las cifras fluctúan entre 30 y $80 \%$ del empleo de los mismos grupos de países. 10

Esa cuestión oculta repercusiones secundarias y terciarias derivadas de la apertura de los mercados. Recuérdese aquí que el acrecentamiento del empleo equivale al aumento del producto, segregado de los avances en la productividad. En consecuencia, la industria siendo el foco vertebral de la productividad, es por lo general un mal empleador, singularmente cuando las empresas manufactureras modernas del Tercer Mundo deben enfrentar la concurrencia de los mejores productores internacionales. La apertura de mercados rompió muchos de los encadenamientos interindustriales multiplicadores de ocupaciones en los países en desarrollo. Entonces, la menor capacidad de absorción industrial de trabajadores, ha debilitado la transferencia de mano de obra proveniente de actividades de baja productividad para engrosar la informalidad.11 A mayor abundamiento, la competencia en mercados abiertos fuerza a las empresas modernas de las zonas en desarrollo a concentrarse en alcanzar mayor eficiencia, aunque ello signifique erosión de los salarios, desplazamiento de trabajadores o vaya en detrimento de dinámica del empleo. 12

9 En México, según el INEGI, desde 2005 la informalidad se ha mantenido cerca de $60 \%$ de la ocupación, superando entre 1 y $2 \%$ la femenina sobre la de los varones.

10 Véase, OІT-OMc (2009), La Globalización y el Empleo Informal de los Países en Desarrollo, Ginebra; ILo (2013), Global Employment Trends, Ginebra.

11 En México el desplome en la tasa de crecimiento industrial ha sido dramático. Entre 1950 y 1982 , el ritmo de ascenso fue de $7.3 \%$ anual. Luego se reduce paulatinamente, aquejada por la década perdida de los años ochenta y el acomodo al neoliberalismo, no promedia más que 0.99\% anual en el periodo 1982-2014. Como consecuencia, cae otro tanto el empleo industrial que apenas sube $0.78 \%$ anual entre 2000 y 2014.

12 Véase, J. A. Ocampo et al. (2009), Growth and Policy in Developing Countries: a Structuralist Approach, Columbia University Press. 


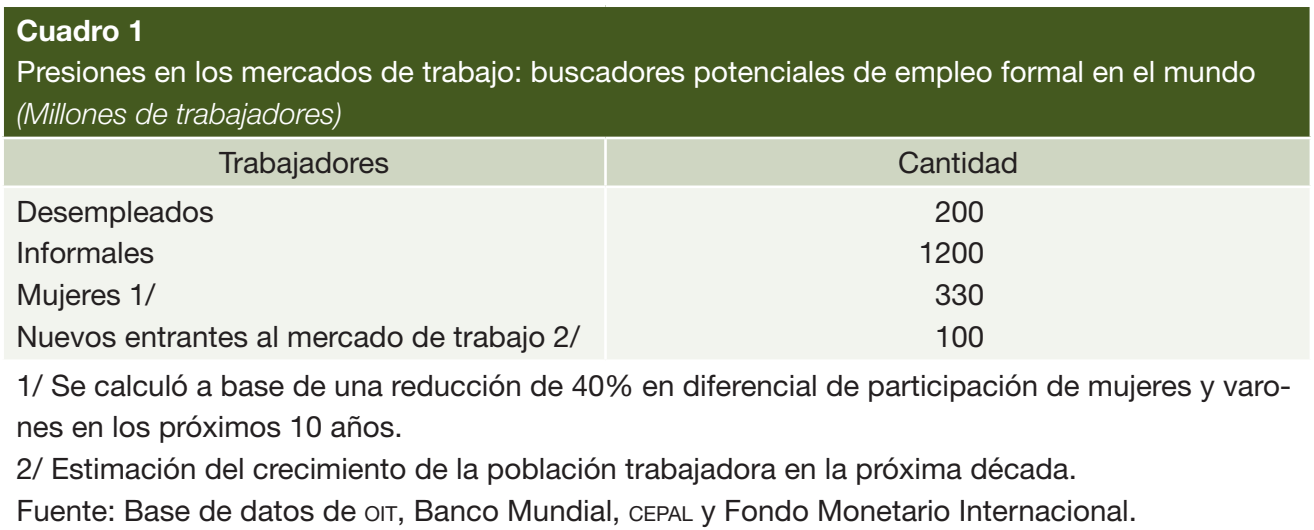

En suma, la magnitud de los desajustes de los mercados mundiales de trabajo alcanza cifras impresionantes. En el cuadro 1, se intenta una cuantificación burda de las tareas a realizar en el mundo para ofrecer ocupaciones mínimamente decorosas a quienes no las tienen: 200 millones de desempleados, 1200 millones de informales o subempleados a los que pronto se añadirían - diez años - 330 millones de mujeres y 100 millones de jóvenes que alcanzarán la edad para trabajar.

El que los mercados de trabajo puedan recuperar cabalmente sus antiguas funciones parece constituir una cuestión en extremo difícil. Aún haciendo caso omiso de la posible generación de tensiones políticas, la solución tomaría demasiado tiempo - décadas - , sin mediar cambios radicales en las concepciones e instituciones de la protección social.

Como señala Picketty 13 sobre la polarización distributiva del ingreso - que priva mientras la tasa de utilidades exceda al ritmo de crecimiento económico - en materia laboral se da un dilema análogo. Mientras el crecimiento de la producción, restado del aumento de la productividad, sea inferior a la expansión de la fuerza de trabajo, no podrán reducirse los excedentes de mano de obra, manifiestos en desempleo, informalidad y lenta incorporación de la mujer y de los jóvenes a las ocupaciones productivas modernas.

\section{Demografía y cambios asociados}

Los diferenciales en ingreso, bienestar y seguridad de los países, así como el menor dinamismo del empleo en muchas de las zonas en desarrollo, originan presiones migratorias enormes que muchos países del Primer Mundo se esfuerzan por contener por razones sociales, culturales y de regulación de sus mercados y presupuestos. En 2005, las migraciones internacionales alcanzaron 191 millones de personas; ya en 2013 sumaron 232 millones, a pesar de restricciones que se multiplican. A lo anterior, se añade la migración creciente de niños indocumentados latinoamericanos a Estados Unidos que plantea un problema humano sin precedente. Entre 1990 y 2013 los migrantes del Sur, asentados en el Norte subieron de 42 a 80 millones, los

13 Véase de nuevo T. Piketty (2014), Capital in the Twenty First Century, Harvard University Press. 
desplazados del Sur a otras localizaciones sureñas crecieron de 59 a 82 millones y los que se movieron dentro del Norte bajaron de 90 a 70 millones. Las cifras anteriores son nítidamente demostrativas de disparidades en los estándares de vida, la pobreza y la acumulación de necesidades insatisfechas, así como del clima de inseguridad que prolifera o se hace crónico. Y al propio tiempo, ponen de relieve presiones en los mercados de trabajo de los países relativamente prósperos que dan pié a ideologías defensivas, incluso contrarias a la vigencia de los derechos humanos. Por eso, las Naciones Unidas han formulado múltiples acuerdos para armonizar las políticas laborales de cada país con los objetivos universales convenidos y, al propio tiempo, asegurar protección a los trabajadores migrantes -con ampliación de las coberturas sociales, mejoras en la contratación, combate a la discriminación. Se trata de esfuerzos encaminados a validar - infructuosamente hasta ahora- los derechos laborales como componente inseparable de los derechos humanos.

Asimismo, los mercados de trabajo y las finanzas públicas resultan, afectados por cambios demográficos y de hábitos sociales. Entre ellos destaca el envejecimiento de la población y la reducción del empleo de jóvenes - sostén, este último, de los regímenes de jubilación-, con generación de cargas significativas a cubrir parcial o totalmente por el gasto de los gobiernos. De ahí cambios a los sistemas de pensiones orientados a transformar los regímenes de beneficios definidos por los de aportes de los trabajadores. La permuta de regímenes quizá alivie los presupuestos de empresas o gobiernos; sin embargo, somete a los trabajadores a los riesgos de la capitalización de sus pensiones en mercados financieros inciertos hoy con tasas de interés deprimidas - , aunados a la inestabilidad de los empleos en mercados de trabajo igualmente deprimidos o volátiles. Son cambios contrarios a la justicia distributiva, precisamente cuando se agudizan las disparidades en los ingresos y riqueza en el mundo y cuando se debilitan los estabilizadores contracíclicos de la demanda de los países.

De otro lado, el propio envejecimiento de la población acentúa las cargas de los sistemas de protección social al asumir los costos del tratamiento de enfermedades degenerativas. Aquí el alivio a los presupuestos públicos y empresariales ha tomado el camino de reducir las coberturas y de recurrir al aseguramiento privado, a los pagos de bolsillo a cargo de los enfermos. De nueva cuenta, los trabajadores pierden derechos, gastos incrementados o asumen mayores riesgos. A su vez, las debilidades de los mercados formales de trabajo, como el de México, suelen nulificar el llamado "bono demográfico" asociado a la disminución de dependientes y al aumento relativo de la población en edad de trabajar, al tiempo que deja desamparados de protección social a los grupos informales. ${ }^{14}$

14 Véanse, C. Cornwell et al. (1998), Pensions and Productivity, Upjohn Institute for Employment and Research, Michigan; A. Blinder (1982), Private Pensions and Public Pensions: Theory and Fact, Working Paper núm. 902, NBeR, Michigan; R. Ham y B. Ramirez (2006), Efectos económicos de los sistemas de pensiones, Colegio de la Frontera, Plaza y Valdés, México; B. Neil y J. Frank (2010), us Pension Reform: Lesson from other Countries, Peterson Institute for International Economics, Washington. 
Acaso los agravios a la equidad distributiva serían menos graves si no coincidieran con la baja casi universal en las tasas de crecimiento de la producción y el empleo (véase el cuadro 2) y por los menores márgenes fiscales de maniobra al sobrevenir la crisis y los salvamentos bancarios en las regiones industrializadas entre otras.

\begin{tabular}{|c|c|c|c|c|c|c|c|}
\hline \multicolumn{8}{|c|}{$\begin{array}{l}\text { Cuadro } 2 \\
\text { Tasas reales de crecimiento del producto }\end{array}$} \\
\hline Período & Mundo & $\begin{array}{l}\text { Estados } \\
\text { Unidos }\end{array}$ & Europa & Japón & Alemania & China & México \\
\hline $1950-1973^{a /}$ & 491 & 391 & 481 & 929 & 568 & 492 & 637 \\
\hline $1973-2003^{a /}$ & 317 & 294 & 219 & 262 & 172 & 734 & 432 \\
\hline 2004-2012 b/ & 390 & 171 & 051 & 081 & 152 & 1055 & 272 \\
\hline $1973-2012 \mathrm{cl}$ & 320 & 261 & 178 & 218 & 164 & 781 & 358 \\
\hline \multicolumn{8}{|c|}{ a/ Las cifras de base son de A. Maddison, The World Economy, OECD, París. } \\
\hline
\end{tabular}

Por su parte, apremios económicos difundidos fuerzan o facilitan la participación de las mujeres en los mercados de trabajo y con alteración de la organización familiar. Sin duda, ello representa avances en igualar los derechos y oportunidades entre sexos, así como en la liberación de talentos y energías femeninas en la vida social. Sin embargo, los efectos positivos quedan supeditados a la capacidad de absorción - no discriminatoria - de los mercados de trabajo, a la organización de ayudas a los hogares, cuidado de niños, enfermos y ancianos.

Sin duda, las políticas macroeconómicas ortodoxas, enderezadas a la consolidación fiscal, al ajuste recesivo, a la par de debilitar a las instituciones y regulaciones del mercado de trabajo, dificultan la incorporación femenina a la producción. La falta de servicios públicos a los hogares, impone cargas desorbitadas a las mujeres y desorganiza la vida familiar. Irónicamente la superación de escollos al empleo femenino, hoy en día, acentúa otros desajustes laborales sobre todo los del pronunciado desempleo juvenil.

\section{Cambio tecnológico y distribución}

Al cambio tecnológico se ha atribuido el desempleo cuasi crónico del mundo industrializado y, en menor medida, la informalidad en las naciones en desarrollo. También suele afirmarse la existencia de un sesgo tecnológico que favorece a la población trabajadora de altas calificaciones y desecha a quienes no alcanzan esos méritos. 15 Sin duda, la intensificación de mudanzas en las formas de producción, la revolución de las comunicaciones, las innovaciones financieras, entre otros muchos factores,

15 Véanse, IMF (2007), World Economic Outlook, The Globalization of Labor, Washington; OECD (2011), Divided we Stand: Why Inequality Keeps Raising, Paris; OECD (2012), Employment Outlook, Paris. 
ha propiciado desplazamientos intersectoriales e intrasectoriales intensos, así como el pago de recompensas a los grupos mejor educados de la población y castigos a quienes no disponen de calificaciones suficientes o no pueden adaptarse a las nuevas circunstancias.

En particular, se aduce la sustitución a mano de obra poco calificada por bienes abaratados de capital, aprovechando las innovaciones incorporadas a la nueva maquinaria; como también la robotización en algunos países inducida por el envejecimiento demográfico o la escasez de mano de obra. Cabe notar, además, los avances en la computación y las comunicaciones, han propiciado el trabajo por cuenta propia, tanto como la proliferación de servicios individuales, como alternativa al empleo en la oficina o en la fábrica.

Junto al cambio tecnológico, influyen poderosamente los desplazamientos geográficoestructurales de la producción, de la tecnología y de la asignación de capitales, compañeros inseparables de la apertura de mercados. En más de un sentido se trata de innovaciones, de modalidades más económicas de producir y comercializar bienes y servicios. Al efecto, las empresas transnacionales fragmentan geográficamente la producción en partes y componentes que luego integran, con menores costos de mano de obra e insumos en redes cada vez más grandes, alimentadas por intensos procesos de fusiones y adquisiciones. 16

En consecuencia, parte substancial del cambio tecnológico consiste en alteraciones institucionales y de políticas anejas al nuevo orden económico internacional que favorecen a determinadas actividades, formas de organización de la producción y abren caminos distintos de hacer las cosas. Asignar mayores funciones a los mercados, restringir el intervencionismo estatal, quitar protección, afectaron sustancialmente a la oferta global y sectorial, a los agentes productivos y, finalmente, el reparto, factorial y entre países del ingreso. Incluso se crean incentivos perversos al acrecentamiento acompasado de salarios y productividad y, en consecuencia, desalentadores del empleo donde quiera que las remuneraciones resulten comparativamente elevadas. Por eso, el abatimiento de los salarios reales en las empresas suele equipararse a la elevación genuina de la productividad.

A partir de esas transformaciones en la vida económica universal se sucede una miriada de acomodos que van conformando la manera postmoderna de hacer economía y política. Por eso, más que tratar de desentrañar caso por caso el impacto de esa maraña de factores del cambio en las instituciones laborales, el análisis podría encaminarse a examinar sus consecuencias, sea en términos de la capacidad de absorción de mano de obra de los mercados de trabajo - como ya se ha hecho- o de su impacto en la distribución factorial y global de ingreso y empleo, como índice de la concentración o dispersión del poder económico y político.

16 Véanse, Banco Mundial (1993), The East Asia Miracle, Oxford University Press, Oxford; J. Stiglitz y H. Yasu (2003), Rethinking the East Asia Miracle, Oxford University Press, N. York; A. Amsden (2001), The Rise of the Rest: Challenges to the West from Late-Industrializing Economies, Oxford University Press, N. York; D. Ibarra 2006), La Reconfiguración Económica Internacional, unAM, México. 
Es innegable en países industrializados o en desarrollo, el crecimiento de la participación del trabajo en el producto muestra claras tendencias, que se hacen viejas, a contraerse. En el cuadro 3 se aprecian sin excepción cifras negativas en la comparación entre los años ochenta y los años 2000, poco antes de la crisis global. Se encuentran las raíces de la alarmante concentración del ingreso que se observa en el mundo, afectando por igual a naciones de distinto grado de desarrollo. 17 Corolario de lo anterior, es la ruptura en la estabilidad de la participación laboral de muchos países industrializados que se habían mantenido incólumes entre la Segunda Guerra Mundial y los años ochenta. En Estados Unidos, no obstante los grandes cambios en el peso de las distintas actividades, entre los primeros años de la posguerra y los años ochenta, la participación de los trabajadores poco se separó de la media del $64 \%$ del producto, poniendo de relieve la estabilidad en la distribución del poder político entre los factores de la producción y un reparto equitativo de los beneficios del avance de la productividad.

\begin{tabular}{|c|c|c|c|c|c|}
\hline \multicolumn{6}{|c|}{$\begin{array}{l}\text { Cuadro } 3 \\
\text { Participacion del ingreso del trabajo en el producto de los paises (Porcientos) }\end{array}$} \\
\hline País & \multicolumn{2}{|c|}{$\begin{array}{l}\text { Comienzos de } 1980 \text { a } \\
\text { comienzos } 1990\end{array}$} & \multicolumn{2}{|c|}{$\begin{array}{l}\text { Comienzos de } 2000 \text { a } \\
\text { comienzos } 2008\end{array}$} & \multirow{2}{*}{$\begin{array}{l}\text { Diferencia } \\
-5.63\end{array}$} \\
\hline Argentina & 38.42 & (noventas) & 32.79 & & \\
\hline Australia & 66.70 & & 62.57 & & -4.13 \\
\hline Brasil & 43.33 & (noventas) & 39.64 & & -3.69 \\
\hline Canadá & 66.89 & & 63.75 & & -3.14 \\
\hline China & 15.58 & & 10.82 & & -4.76 \\
\hline Francia & 71.44 & & 65.87 & & -5.57 \\
\hline Alemania & 67.11 & & 63.37 & & -3.74 \\
\hline India & 34.03 & & 32.18 & & -1.85 \\
\hline Italia & 68.70 & & 62.37 & & -6.33 \\
\hline Japón & 72.38 & & 65.75 & & -6.63 \\
\hline Corea, República de & 81.62 & & 76.97 & & -4.65 \\
\hline México 1/ & 40.60 & (1976) & 28.10 & (2008) & -12.50 \\
\hline Federación Rusa & 45.87 & (noventas) & 45.56 & & -0.31 \\
\hline Sud Africa & 56.65 & & 50.18 & & -6.47 \\
\hline Turquía & 48.07 & & 50.34 & & 2.27 \\
\hline Reino Unido & 72.98 & & 70.73 & & -2.25 \\
\hline Estados Unidos & 68.20 & & 65.87 & & -2.33 \\
\hline Estados Unidos 2/ & 64.00 & (mediados de los 80) & 58.00 & & -6.00 \\
\hline
\end{tabular}

Fuentes: M. Lavoie y E. Stockhammer (2013), Wage-Led Growth, Palgrave, Inglaterra; 1/ Para México, Nacional Financiera (1985) La Economía Mexicana en Cifras 1984, México; INEGI (varios números) Sistema de Cuentas Nacionales de México, México; 2/ Para los Estados Unidos la segunda medida fue tomada de Elsby, M. et al. (2013) "The Decline of the U. S. Labor Share", Brookings Papers on Economic Activity, pp. 1-52, Washington.

17 El caso de México es escandaloso. Los salarios mínimos y los contractuales del sector moderno de la economía entre la década de los setentas del siglo pasado y la actualidad se han comprimido en términos reales más de $70 \%$ en el primer caso y más de $20 \%$ en el segundo. Por su parte, la participación salarial en el producto ha caído de $41 \%$ a $28 \%$ en el periodo 1980-2008. 
Quiérase o no, el encogimiento relativo de las remuneraciones al trabajo es demasiado general para ser explicado por el abaratamiento en los precios de los bienes de capital y de las innovaciones incorporadas a los mismos, como inductores de la robotización y del reemplazo de trabajadores por maquinaria y de la reducción consiguiente de los salarios frente a las utilidades empresariales. ${ }^{18}$ Más que profundización con el uso de bienes de capital en las empresas, se observan alteraciones intersectoriales geográficas en la producción, en la generación de valor agregado que alteran de distintas maneras el peso de la participación de los trabajadores en el ingreso. En efecto, las repercusiones de los trastornos y cambios en los centros productivos mundiales, dan origen a procesos costosos de ajuste que sufren principalmente los trabajadores y sindicatos en comparación mayores a los que padecen las empresas. Y junto a lo anterior se observa clara erosión de la influencia política de sindicatos y trabajadores que les impidan luchar para evitar el deterioro salarial y la concentración del ingreso, dentro de los países y, desde luego, a escala global.19 Los acomodos resultantes se expresan en sufrimiento humano, desempleo, salarios precarizados, pérdida de derechos y reparto desigual de los beneficios del ascenso de la productividad.20

\section{El impacto diferencial de la inversión y el ahorro}

Con excepción de China y pocos países más, la desindustrialización o la baja en los ritmos de industrialización de muchas naciones y el auge de los servicios, ocasionan desplazamientos dinámicos fuera de los sectores con remuneraciones relativamente altas al trabajo.21 Con todo, el hecho más significativo en la participación del trabajo en el valor agregado, está relacionado a los efectos de la globalización en la distribución de la producción y de la inversión en el mundo. El que la economía China durante periodos considerables crezca a tasas cercanas a $7-10 \%$ y con menos intensidad otro tanto ocurra en varios países emergentes, mientras buena parte de las naciones

18 Contradiciendo esa hipótesis, en los Estados Unidos no coinciden las actividades sectoriales de salarios más deprimidos con aquéllos donde ha tenido lugar "capital deepening". Tampoco parecen coincidir los sectores con declinación mayor en los precios de los bienes de capital con las reducciones más agudas de la participación de los salarios en el producto. (Véase, Elsby M. et. al. (2008), Unemployment Dynamics in the OECD, NBER, Working Paper núm. 14617).

19 A título ilustrativo, entre 1994 y 2013, ha tenido lugar elevación moderada de la productividad laboral mexicana que ya ocupa el segundo lugar en América Latina. En contraste, los salarios mínimos reales se han desplomado al menos $25 \%$ y los contractuales cerca de $20 \%$ (Véase, J. C. Moreno-Brid (2014), Vecinos distantes: productividad laboral y salarios mínimos reales, inédito, Fundación Friederich Ebert, México).

20 Véase, C. Hollweg et al. (2014), Sticky Feet, How Labor Market Frictions Shape the Impact of International Trade on Jobs and Wages, The World Bank, Washington.

21 En México, entre 1950 y 2014, la tasa de crecimiento industrial pasó de exceder de 7\% a 1\% anual. En contraste los servicios - refugio de mucha de la informalidad- mantienen desde 1982 con ritmo de ascenso cercano al doble de la industria (1.76\%). Visto en un periodo más corto (20002014) y desde el punto de vista del empleo, la ocupación industrial apenas creció a $0.8 \%$ anual, mientras la de los servicios lo hizo a 2.15 por ciento. 
industrializadas registran alzas pobres o recesivas, dan pié a mudanzas enormes en los centros de gravitación de la economía mundial.22 Concentrar la inversión mundial a los países donde se había acumulado la mano de obra subempleada o redundante $-y$, en consecuencia comparativamente mal pagada - sitúa el meollo de la competencia mundial en los mercados de trabajo.

Las diferencias en tasas de crecimiento se asocian a marcadas discrepancias en la realización de inversiones productivas nuevas y a la generación de ahorros entre países. En las economías desarrolladas, la inversión y, ligeramente por debajo, el ahorro, han fluctuado alrededor de $22 \%$ del producto desde 1984 . En contraste, las mismas variables en los países en desarrollo son entre dos y cuatro puntos mayores. Pero, en las naciones emergentes de Asia, suben significativamente de 35\% (ahorro) y $28.7 \%$ (inversión) en los promedios $1984-1991$ a $36.8 \%$ y $31.1 \%$ en el periodo 1992-1999, hasta llegar, entre 1999 y 2007, a $44.1 \%$ y $42.0 \%$, también respectivamente (véase el cuadro 4). Los distintos ritmos de ahorros y de capitales están transformando las capacidades de producción y empleo entre los países, como fenómeno medular de la globalización.

\begin{tabular}{|c|c|c|c|}
\hline \multicolumn{4}{|c|}{$\begin{array}{l}\text { Cuadro } 4 \\
\text { Ahorro e inversiones mundiales (Porcientos del producto) }\end{array}$} \\
\hline & 1984-1991 & $1992-1999$ & 2000-2007 \\
\hline \multicolumn{4}{|l|}{ Mundo } \\
\hline Ahorro & 22.9 & 22.7 & 23.1 \\
\hline Inversión & 23.7 & 23.5 & 23.1 \\
\hline \multicolumn{4}{|c|}{ Naciones en desarrollo } \\
\hline Ahorro & 22.3 & 23.7 & 28.8 \\
\hline Inversión & 23.0 & 28.8 & 26.2 \\
\hline \multicolumn{4}{|c|}{ Naciones asiáticas emergentes } \\
\hline Ahorro & 35.1 & 36.8 & 44.1 \\
\hline Inversión & 28.7 & 31.1 & 42.0 \\
\hline
\end{tabular}

Fuente: FMI (varios números) World Economic Outlook, Washington.

Con la integración de los mercados financieros, la inversión extranjera directa cobra importancia como vehículo distribuidor de la formación mundial de capital. Y, a la par, cambia de significación ideológica al considerarla no como artificio de sujeción a los países avanzados, sino como vía de escape a las limitaciones financieras (divisas) y del ahorro propias del subdesarrollo. De cifras no mayores a 2-3\% de la formación total de capital en el mundo, la inversión foránea ha llegado a representar más del 18\% del total y su magnitud anual no ha bajado de 6-7\% (véase el cuadro 5). Hoy en día, la acumulación de reservas internacionales (34\% del total mundial) y sus superávits

22 Desde la década de los setenta en el siglo pasado, los países emergentes de Asia vienen creciendo a razón del $6 \%$ o más cada año, mientras los países industrializados no rebasan en promedio el $3 \%$. Por eso y por su peso demográfico se pronostica que China en pocos años más igualará tamaño de la economía norteamericana. 
en el intercambio comercial, transforman a China en exportadora de capitales (5\% de su producto), con desplazamiento gradual de las viejas naciones industrializadas.

\begin{tabular}{|c|c|c|c|}
\hline \multicolumn{4}{|c|}{$\begin{array}{l}\text { Cuadro } 5 \\
\text { Formacion mundial de capital y flujos de inversion extranjera } \\
\text { (Miles de millones de dólares y porcientos) }\end{array}$} \\
\hline \multirow{2}{*}{ Año } & \multirow{2}{*}{$\begin{array}{c}\text { Formación mundial de capital } \\
\text { Dólares }\end{array}$} & \multicolumn{2}{|c|}{ Inversión Extranjera directa } \\
\hline & & Dólares & $\%$ \\
\hline 1992 & 5553.5 & 166 & 3.0 \\
\hline 1993 & 5770.7 & 223 & 3.9 \\
\hline 1994 & 6437.9 & 256 & 4.0 \\
\hline 1995 & 7165.4 & 344 & 4.8 \\
\hline 1996 & 7403.3 & 391 & 5.3 \\
\hline 1997 & 7419.9 & 488 & 6.6 \\
\hline 1998 & 7174.8 & 706 & 9.8 \\
\hline 1999 & 7337.5 & 1091 & 14.9 \\
\hline 2000 & 7596.6 & 1413 & 18.6 \\
\hline 2001 & 7367.1 & 836 & 11.3 \\
\hline 2002 & 7612.9 & 626 & 8.2 \\
\hline 2003 & 7927.3 & 601 & 7.6 \\
\hline 2004 & 9300.6 & 734 & 7.9 \\
\hline 2005 & 10452.0 & 990 & 9.5 \\
\hline 2006 & 11660.5 & 1481 & 12.7 \\
\hline 2007 & 13485.6 & 2003 & 14.9 \\
\hline 2008 & 14837.5 & 1816 & 12.2 \\
\hline 2009 & 12716.6 & 1216 & 9.6 \\
\hline 2010 & 14653.9 & 1409 & 9.6 \\
\hline 2011 & 17058.5 & 1652 & 9.7 \\
\hline 2012 & 17692.9 & 1351 & 7.6 \\
\hline
\end{tabular}

Fuente: base de datos de la UNCTAD y del FMI.

\begin{tabular}{|c|c|c|c|c|c|c|}
\hline \multicolumn{7}{|c|}{$\begin{array}{l}\text { Cuadro } 6 \\
\text { Acervos de inversion extranjera directa (Miles de millones de dólares) }\end{array}$} \\
\hline & \multicolumn{2}{|c|}{1990} & \multicolumn{2}{|c|}{2000} & \multicolumn{2}{|c|}{2013} \\
\hline & Dólares & $\%$ & Dólares & $\%$ & Dólares & $\%$ \\
\hline Mundo & 2078.3 & 100 & 7511.3 & 100 & 24536.1 & 100 \\
\hline Desarrollados & 1563.9 & 75 & 5682.0 & 76 & 16053.1 & 65 \\
\hline En desarrollo & 514.3 & 25 & 1771.5 & 24 & 8483.0 & 35 \\
\hline China & 20.7 & 1 & 193.3 & 3 & 956.8 & 4 \\
\hline América Latina y Caribe & 111.4 & 6 & 507.3 & 7 & 2568.6 & 10 \\
\hline
\end{tabular}


Los acervos de inversión extranjera en el mundo han crecido espectacularmente entre 1990 y 2013 (doce veces), más que el comercio exterior (4 o 5 veces), alimentando desarrollos diferenciales entre países, así como a un intenso proceso de adquisiciones y fusiones, propio de la oligopolización de la producción global (véanse cuadros 6 y 7). Los cambios de dirección se inclinan hacia los países en desarrollo de mano de obra e insumos baratos y de mercados internos amplios. La participación de este último grupo en el acervo total del mundo ha crecido significativamente en $10 \%$, mismo porcentaje que pierden los países industrializados. Con todo, el país con mayores atractivos ha sido China, cuyos acervos suben 46 veces en el periodo indicado, aunque lo hace desde niveles inicialmente reducidos. América Latina también ha sido favorecida con inversiones en rápido ascenso que multiplican su acervo 23 veces. Sin embargo, el impacto de la inversión extranjera en el desarrollo de ambas regiones ha resultado notoriamente distinto. Alto en el caso chino, mucho menos relevante en el latinoamericano. 23

23 Acaso la diferencia medular estriba en que la inversión extranjera en China -junto con otros controles regulatorios - se dirigió a desarrollar capacidades de oferta y empleo previamente inexistentes y a establecer nexos de asociación e integración con redes internas y externas de comercio y producción. En contraste, en América Latina la venta de empresas públicas y privadas absorben buena parte de las remesas foráneas recibidas, sin que las políticas internas se hayan dirigido sistemáticamente a reforzar las vinculaciones intra e intersectoriales propias o las internacionales. En las últimas tres décadas la notable expansión del mercado chino requirió completar su oferta con inversión extranjera repetitiva como si fueren recursos enteramente nuevos o frescos (greenfield) en el país. Asimismo, han influido las connotaciones distintas de las políticas industriales y macroeconómicas en el impacto diferencial entre América Latina y China de la inversión extranjera en el empleo y el crecimiento. Por otro lado, destacan las enormes dimensiones y la capacidad expansiva interna del ahorro chino que facilita apreciablemente la concreción de su industrialización y de sus vinculaciones internas e internacionales, mientras el ahorro latinoamericano ha permanecido concentrado y estable en términos de su peso en el producto. 


\begin{tabular}{|c|c|c|c|c|c|}
\hline Cuadro 7 & $\begin{array}{l}7 \\
\text { s y adquisiciones }\end{array}$ & nsfronteriza & e millones de & lares y porcie & \\
\hline \multirow{2}{*}{ Año } & \multirow{2}{*}{$\begin{array}{l}\text { Flujos Inversión } \\
\text { Extranjera } \\
\text { Directa Dólares }\end{array}$} & \multicolumn{2}{|c|}{ F. y A. Transfronterizas } & \multirow{2}{*}{$\begin{array}{l}\text { F. A. } \\
\text { Mundial } \\
\text { Respecto a } \\
\text { IED } 2 / 1 \%\end{array}$} & \multirow{2}{*}{$\begin{array}{l}\text { F. A. Países } \\
\text { desarrollados } \\
\text { con respecto al } \\
\text { total } 3 / 2 \%\end{array}$} \\
\hline & & $\begin{array}{l}\text { Mundial } \\
\text { dólares }\end{array}$ & $\begin{array}{l}\text { Países } \\
\text { Desarrollados } \\
\text { dólares }\end{array}$ & & \\
\hline 2000 & 1413 & 1144 & 1088 & 81 & 95 \\
\hline 2001 & 836 & 594 & 534 & 71 & 90 \\
\hline 2002 & 626 & 369 & 323 & 59 & 88 \\
\hline 2003 & 601 & 297 & 244 & 49 & 82 \\
\hline 2004 & 734 & 381 & 317 & 52 & 83 \\
\hline 2005 & 990 & 716 & 605 & 72 & 84 \\
\hline 2006 & 1481 & 880 & 728 & 59 & 83 \\
\hline 2007 & 2003 & 1045 & 916 & 52 & 88 \\
\hline 2008 & 1816 & 626 & 480 & 34 & 77 \\
\hline 2009 & 1216 & 285 & 237 & 23 & 83 \\
\hline 2010 & 1409 & 349 & 260 & 25 & 74 \\
\hline 2011 & 1652 & 556 & 439 & 34 & 79 \\
\hline 2012 & 1351 & 332 & 269 & 25 & 81 \\
\hline 2013 & 1451 & 349 & 240 & 24 & 69 \\
\hline
\end{tabular}

Fuente: UNCTAD, World Investment Report, varios números

Junto al auge de la inversión extranjera de las últimas dos décadas, cobra vigencia el proceso paralelo de fusiones y adquisiciones que da forma y consolida a las grandes redes de producción e intercambio, refuerza el poder político de las empresas transnacionales y explica una parte de los desplazamientos geográficos de la demanda de mano de obra. En los últimos años, las fusiones y adquisiciones no han dejado de representar menos de la cuarta parte de los flujos mundiales de inversión extranjera y, aunque han tendido a disminuir, en ocho de los trece años analizados, ascendieron a más de la mitad (véanse de nuevo los cuadros 5,7 y el 8), principalmente impulsados aunque de manera decreciente por empresas de los países industrializados al construir sus redes oligopólicas globales. 
Cuadro 8

Proyectos frescos (greenfield) como porcentaje del flujo de inversion extranjera directa (Porcientos)

\begin{tabular}{|c|c|c|}
\hline Año & América Latina & China \\
\hline 2008 & 8.9 & 47.0 \\
\hline 2009 & 10.2 & 25.5 \\
\hline 2010 & 11.5 & 20.7 \\
\hline 2011 & 8.5 & 40.1 \\
\hline 2012 & 3.7 & 19.2 \\
\hline 2013 & 6.3 & 19.3 \\
\hline
\end{tabular}

Fuente: preparado con datos de la UnCTAD (2014), World Investment Report, Ginebra.

Vistos los distintos fenómenos en juego, el descenso en la participación de los trabajadores en el ingreso de los países, obedece principalmente a la exposición a la competencia internacional, acentuada o explicada por el cambio geográfico de la formación de capital -incluida la inversión extranjera- y de la generación de los ahorros, consecuencia del peso cambiante de los centros mundiales de producción y empleo. Las actividades más comprometidas por la concurrencia externa o las excluidas de las grandes redes trasnacionales son las que más han visto reducir sus actividades y las que más han debido bajar empleo y salarios. No significa lo anterior que el cambio tecnológico, el debilitamiento de la negociación colectiva, la reducción de las membresías sindicales, las burbujas financieras, no tengan importancia. La tiene, sin embargo, el factor distributivo fundamental que origina o influye en esos hechos, nace de la implantación del nuevo orden internacional con su apertura comercial y financiera, así como del cambio institucional y de políticas que la hacen y la han hecho factible a escala universal y de los países.

\section{Consideraciones finales}

Las políticas sociales en la mayor parte del mundo enfrentan desadaptación y limitaciones crecientes para brindar protección a las poblaciones y legitimar a los gobiernos nacionales. En particular, los mercados de trabajo en tanto, institución armonizadora entre economía y democracia, encaran más y más debilidades en la conciliación de los intereses de las clases sociales entre sí, con los gobiernos y con las grandes corporaciones. A diferencia de otras épocas no hay más que barruntos de nuevos planteamientos paradigmáticos de los que se pudiesen derivar reformas a los mercados de trabajo y a la propia política de protección social a escala nacional y global.

La reducción universal en las tasas de crecimiento, el ascenso brutal de la concentración del ingreso, la contracción relativa de los salarios (véanse de nuevo los cuadros 2 y 3) tipifica el angostamiento de la demanda efectiva para crear suficientes puestos de trabajo y validar inversiones frescas. Las capacidades de oferta, exceden el poder acotado de compra de las poblaciones. Por consiguiente, la globalización y los cambios tecnológicos producen dislocaciones de los mercados nacionales de 
trabajo que inciden y rebasan a las políticas nacionales de protección social a las poblaciones.

Hoy en día, los gobiernos lejos de responsabilizarse exclusivamente por los mandatos de sus congresos y ciudadanos, deben acomodarlos lo mejor que pueden a demandas imperativas de actores externos - potencias líderes, corporaciones y autoridades transnacionales, convenios de igual índole- así como las de las elites privadas nacionales, frecuentemente aliadas a los actores foráneos. Hasta el lenguaje cambia, menos y menos se habla del gobierno y más y más de gobernanza, esto es, poder compartido con los poderes fácticos. Al propio tiempo, la noción de soberanía es sustituida para todo fin práctico por la de cogobierno público-privado. Así se respalda el paradigma de la competencia, más que resguardar la cohesión política interna.

Esos fenómenos junto a las notorias vulnerabilidades sociales, desacreditan los procesos de la democracia. Recuérdese que el gran acomodo del siglo xx entre democracia y mercado, consistió en resguardar a la primera de interferencias abusivas del poder económico y en otorgar primacía a los gobiernos en las decisiones referidas a protección social y al empleo. Se intentaba de evitar o moderar los posibles efectos desestabilizadores del conflicto social y los no menos dañinos de las crisis económicas. Ese pacto fundamental fue roto por el neoliberalismo que postuló y ganó la supremacía de lo económico sobre lo político, como vía única al desarrollo económico del mundo globalizado. Y al propio tiempo, logró que las decisiones políticas no enturbiasen el funcionamiento de los mercados más que en el margen, dejando vía libre la transformación de poder económico en poder político. De aquí el desapego paulatino de la población con respecto a los sistemas democráticos, evidenciado en la participación descendente del voto electoral.

En efecto, los estratos más numerosos y menos favorecidos de la población frente a decisiones contrarias a sus intereses, pierden confianza en el sistema político que debiera oírles y atenderles. La desigualdad y las políticas de solución a la crisis mundial (consolidación fiscal, alza de impuestos indirectos, poda a los salarios y al Estado benefactor, aceptación de alto desempleo, populismo financiero, en suma, austeridad diferenciada), carga los costos del ajuste en los grupos más numerosos de las poblaciones y, al propio tiempo, desprestigia a congresos, gobiernos y a la representatividad de los resultados electorales. ${ }^{24}$ Quizá como respuesta, desde los años setenta, casi sin excepción, la participación en las elecciones parlamentarias del Mundo Occidental se ha reducido entre 10 y 20 puntos. 25 Adviértase además, que los ciudadanos de ingresos elevados, mejor educados, tienden a votar más que

24 Véanse, P. Mair (2006), "The Hollowing of Western Democracies", New Left Review 42, pp. 2551; C. Wood (2002), "Voter Turnout in City Elections", Urban Affairs Review, núm. 38, pp. 209231; P. Norris (2011), Democratic Deficit, Cambridge University Press; M. Gilens (2012), "Affluence and Influence", Economic Inequality and Political Power in America, Princeton University Press; A. Schafer y W. Streeck (2013), Politics in the Age of Austerity, Polity Press, Inglaterra.

25 Un fenómeno semejante ocurre con la membresía sindical que se erosiona en el mundo, como reflejo del agotamiento de la efectividad de la fuerza opositora de las organizaciones obreras frente a las políticas contrarias a sus demandas e intereses. 
el resto de la población. Y, ello también sesga a favor de sus intereses las políticas públicas sensibles a los comicios. 26

La crisis de 2008 ha puesto de relieve que los mercados de trabajo lejos de estar afectados sólo por problemas cíclicos, reconocen fallas estructurales de fondo, que hacen difícil corregir las elevadas, crónicas, tasas de desempleo en los países industrializados y la informalidad de muchas economías en desarrollo (véase de nuevo el cuadro 1). Ambos fenómenos exacerban las dislocaciones distributivas en un contexto de competencia oligopolística internacional, al tiempo que anticipan una recuperación mundial mediocre que tendrá poca mella en absorber los excedentes mundiales de mano de obra. 27 El trabajo, desnudo de normatividad protectora pasa a ser visto como una mercancía más y el salario como un costo de producción que debe abatirse en aras de ganar competitividad.

Obsérvese que la innovación tecnológica y la concurrencia por fuerza transnacionalizada de productores, tienen muchos efectos positivos, pero deprime la demanda de trabajo aparejada al crecimiento sobre todo de los sectores modernos de los países en desarrollo. Nótese que el mismo cambio tecnológico e institucional altera el peso de los sectores líderes de las economías, desplaza a la fábrica como lugar de concentración y concertación con la mano de obra, a la par de facilitar la individualización del trabajo. Adviértase, además, que la competitividad en mercados abiertos favorece la concentración de la inversión y el empleo mundiales en las naciones emergentes de bajos costos y amplios mercados, al tiempo que alienta la vertebración de la producción y el intercambio en grandes redes; fenómenos todos condicionantes, cuando no reduccionistas, de los alcances de la acción desarrollista de los gobiernos.

A esos hechos, se suman los otros fenómenos mencionados - cambios demográficos, presiones migratorias, erosión del orden familiar, apremios presupuestarios - que inciden la erosión de los mercados nacionales de trabajo. Todo ello, disloca los tres pilares fundamentales de la protección social: la población, el Estado, las empresas y las propias familias, recreando la desigualdad de fortunas que ya se creía periclitada. El primero falla por carencia crónica de recursos, frecuentemente acentuada por endeudamientos excesivos; las segundas, al hacer de los salarios una carga a abatir en la contienda competitiva de mercados abiertos; la tercera por

26 En México, pese haberse dado frecuentes acontecimientos distorsionantes - alternancia política en el gobierno, ascenso de la izquierda, regreso del PRI-, parece configurarse un fenómeno análogo. La participación de votantes con respecto al padrón electoral ha caído de $77.2 \%$ en 1994 a $63.1 \%$ en 2012 en la elección presidencial. Más aún, las actuales divisiones dentro los partidos de derecha e izquierda y, hasta hoy, la incapacidad gubernamental de reactivar el crecimiento, plantean un escenario complejo que podría revertir o bien, intensificar la abstinencia electoral. Y, sin embargo, hay clara inclinación de participación de los grupos populares, manifiesta en las multitudinarias y repetidas marchas ciudadanas para protestar o demandar acciones de las políticas públicas.

27 Véanse, M. Daly et. al. (2012), "Did the Natural Rate of Unemployment Rise?", Journal of Economic Perspectives, vol. 26, núm. 3, pp. 3-26; M. Daly y B. Hobijn (2010), Okun's Law and the Unemployment Surprise of 2009, Federal Reserve Bank of San Francisco (Véase de nuevo, M. Elsby et. al. (2008), Unemployment Dynamics in the OECD, NBER, Working Paper núm. 14617). 
el desempleo, la informalidad y la incorporación femenina al mercado de trabajo, la concentración del ingreso.28

Por eso, es casi inescapable admitir que los pactos sociales base de la conciliación histórica entre democracia y mercado han quedado rebasados cuando los nuevos paradigmas económicos globales produjeron menor crecimiento global, crisis repetitivas, desigualdades y tensiones sociales a la larga insostenibles. Se olvida que el ordenamiento de los mercados abiertos necesita de regulaciones y prelaciones que debieran convenirse entre los estados para acotar la transformación del poder económico en poder político y limitar la desprotección social en ascenso. El trabajo es algo más que una mercancía y el salario algo más que un costo de producción. La racionalidad de la competencia - necesariamente concentradora del ingreso-, sólo al precio de la descomposición social puede tomar lugar de la democracia en el resguardo de justicia, equidad e igualdad asequibles a todos los ciudadanos. En consecuencia, el manejo macroeconómico, junto a la salud de los sistemas financieros y debiera impulsar con igual o mayor prelación a la inversión, crecimiento, empleo y distribución equitativa de ingresos, sin olvidar la escasez planetaria intrínseca de recursos naturales. Por supuesto, esos y otros cambios necesarios, enfrentan resistencias casi insalvables al anticipar un orden internacional distante del que nos rige y de los intereses constituidos.

Y, sin embargo, poco se avanzaría en el remozamiento indispensable de los pactos sociales y en la solución a la crisis global, sin brindar a la democracia la oportunidad de aliviar las rupturas, que hoy por hoy desgajan al mundo. Con todo, es prematuro esperar la revisión del orden económico internacional y quizá también lo sea, confiar a escala de los países en que los gobiernos retomen las riendas de las economías hasta hacer prevalecer el interés general sobre los intereses privados.

Adentrarse en esas cuestiones rebasa con mucho los alcances de este trabajo. En consecuencia, los señalamientos se limitarán a las cuestiones que más directamente conciernen al empleo y a la protección social de las poblaciones. Aquí la prelación debiera enfocarse a la reconstrucción de los estados sociales de bienestar por imperfectos o desgastados que sean, a dar solidez a los derechos humanos básicos, sobre todo los que atañen a los servicios educativos, de salud y a las pensiones o jubilaciones.

Aún a escala del empleo y de la oferta de protección social, se precisaría abordar medidas difíciles de asimilar por las ideologías dominantes, aún siendo necesarias para enmendar las rupturas de los pactos sociales y la obsolescencia de los mercados de trabajo. Una acción relevante consistiría en independizar los derechos de protección social de la incorporación obligada de la mano de obra al sector moderno de los mercados de trabajo. La legislación social del futuro en vez de tejerse en torno al trabajo formal, poco a poco tenderá a forjarse en torno a derechos sociales exigibles por

28 Véase, Esping-Andersen (1985), Politics against Markets, Princeton University Press; (2004), "After the Golden Age? Welfare State Dilemmas in a Global Economy", Welfare States in Transition, SAGE Publications, Londres. 
todos los ciudadanos, como ya comienza a ocurrir en varios países.29 Así lo aconseja observar el desbarajuste de los mercados de trabajo, el ascenso vertical de los grupos sin derechos o con derechos truncos a la protección social, así como los tiempos prolongadísimos tomaría absorber los excedentes de mano de obra (desempleados, informales, mujeres, jóvenes), a escala nacional y global.

Emprender lo anterior, por fuerza llevaría a modificar estructura del gasto público y también las fórmulas tradicionales del financiamiento de los servicios sociales (gravámenes al trabajo, contribuciones bipartitas o tripartitas, aportes voluntarios o filantrópicos) a fin de cubrirlos con la recaudación directa de impuestos generales y progresivos. Aquí, sería necesario recurrir al Impuesto sobre la Renta debido a su capacidad de corregir la distribución primaria, altamente concentrada del ingreso, aparte de su aporte a cubrir el incremento del gasto social resultante. ${ }^{30}$ De ese modo, se ofrecería acceso permanente a los servicios a la población desprotegida, aún a la afectada por desempleo, al tiempo que se fortalecerían los estabilizadores contracíclicos de la demanda agregada.

Las ventajas de proceder de esa manera serían múltiples, se aliviaría o acortarían las fases depresivas de las economías, se reducirían la vulnerabilidad de los derechos sociales, se equilibrarían la distribución de beneficios de las políticas públicas - hoy sesgada al extremo por los bajos salarios - y se dejarían de recargar con impuestos los costos laborales. En suma, la seguridad social pasaría de ser privilegio exclusivo del asalariado del sector moderno de las economías a constituirse en garantía exigible de todo ciudadano.

En rigor, la universalización de los accesos a los servicios sociales esenciales resolvería parcialmente la cortedad de alcances de las políticas e instituciones de la protección a las poblaciones. Sin embargo, sólo indirectamente contribuirá a subsanar la insuficiencia de la demanda de empleo o los bajos salarios o la falta resultante de ímpetu de la demanda agregada. En consecuencia, si persistiera el carácter excluyente o la depresión salarial de los mercados de trabajo, si no resultase pronta la absorción de los excedentes de mano de obra, si la multiplicación de las ocupaciones por cuenta propia fuese irrefrenable, habría que fortalecer sin tapujos la demanda por la vía de inyectar poder adquisitivo a los estratos desprotegidos de la población. ${ }^{31}$ Así

29 Véanse, G. Pisarello (2007), Los derechos sociales y sus garantías, Trotta, Madrid; V. Abramovich y C. Curtis (2004), Los Derechos Sociales como Derechos Exigibles, Trotta, Madrid; C. Offe et al. (1996), Basic Income Guaranteed by the State, Modernity and the State, The Mit Press, Cambridge, Mass. U. S. A.; D. Ibarra (2012), "Mercado de trabajo y protección social" en la crisis inacabada, Facultad de Economía, unAm, México; D. Ibarra (2007), "Derechos Humanos y Realidades Sociales", en L. Orcí y V. M. Martínez Bullé, Los Derechos Humanos, Económicos, Sociales y Culturales, Comisión Nacional de los Derechos Humanos, México.

30 A título ilustrativo, en México las estimaciones de la concentración del ingreso lo sitúan como uno de los países con mayor desigualdad. La participación de $1 \%$ más rico de la población se estima en $21.3 \%$ del producto y coincide con una de las economías de más baja recaudación impositiva (10\% del producto). (Véase, R. Campos et. al. (2014), Los ingresos altos, la tributación óptima y la recaudación posible, inédito, México).

31 Aparte de las referencias de la nota 25. (Véanse, J. Rawls (1997), Teoría de la Justicia, Fondo de Cultura Económica, México; G. Pisarello y de A. Cabo (2006), La renta básica como nuevo de- 
se lograría simultáneamente mejorar el reparto del ingreso y estimular a los mercados de bienes y servicios. La solución residiría en establecer ingreso mínimo garantizado a todos los ciudadanos, la llamada Renta Básica, que fortalecería distributiva y políticamente a la mano de obra, a las mujeres trabajadoras y a los hogares monoparentales. Al mismo tiempo, se podrían suprimir por innecesarios una larga serie de programas sociales focalizados, como las ayudas y subsidios en combate a la pobreza. 32

Sin duda, el planteamiento de la Renta Básica encuentra y encontrará opositores. De un lado, restaría fuerza disciplinaria a empresas y al mercado de trabajo sobre la mano de obra y hasta podría ser visto como otro elemento debilitador de la menguada influencia sindical. De otro lado, por más que llevara a suprimir erogaciones sociales que resultarían redundantes, el esfuerzo recaudatorio adicional, no sólo provocaría la oposición de los partidarios de la austeridad presupuestaria, sino de quienes rechazan las bondades de los impuestos progresivos.

Sin duda, la viabilidad de la universalización de los servicios sociales y luego el derecho a una renta mínima garantizada mucho depende de la situación fiscal financiera y política de cada país. En todo caso, podría procederse por etapas hasta finiquitar la reforma. Pasos modestos podrían consistir en otorgar ingresos a la población de edad avanzada - como ocurrió en la ciudad de México33 - , establecer o extender en el tiempo el seguro de desempleo,34 o proceder a la generalización parcial de los accesos a la salud pública, incorporando a desempleados y trabajadoras domésticas, sobre todo en los países en desarrollo carentes de estos derechos.

recho ciudadano, Trotta, Madrid; A. Sen (2006), El valor de la democracia, Viejo Topo, Barcelona; J. Noguera (2001), La renta básica y el principio contributivo, Ariel, Barcelona; D. Raventós et. al. (2012), "Renta básica ciudadana", Sin Permiso, México).

32 A título ilustrativo, en 2010, el Consejo Nacional de Evaluación de la Política Social de México consignó un enorme inventario de 273 programas sociales paliativos que atienden fragmentaria y desordenadamente demandas sociales insatisfechas. A pesar de ello, serias carencias atenazaban a $80.7 \%$ de la población, donde $46.5 \%$ vivía en la pobreza y $10.4 \%$ en la indigencia.

33 En la ciudad de México, casi medio millón de personas de edad avanzada, goza de una renta jubilatoria subsidiada, casi equivalente a la canasta básica del propio Distrito Federal, con la única condición de tener residencia de tres años en dicho lugar. Además, a través del "Seguro Popular" que se extiende a todo el país, se quiere dar un paso modesto hacia la universalización de los derechos a la salud.

34 También en México existe una iniciativa de Ley para establecer el seguro de desempleo (recuérdese que entre los países miembros de la OCDE, México es el único cuyos trabajadores carecen de ese derecho). En principio, la idea es constructiva al abrir un cauce que inicia el perfeccionamiento de los derechos laborales. Sin embargo, la iniciativa es notoriamente débil. De un lado, sólo está referida a los trabajadores del sector formal de la economía (4 de cada 10); excluye a los trabajadores del sector público e impone requisitos de acceso y de goce de beneficios extraordinariamente restrictivos conforme a las prácticas internacionales. De otro, tiene como principal fuente de financiamiento los aportes a la cuenta de vivienda del INFONAVIT que necesariamente limita o encarece los préstamos a las casas y departamentos de los propios trabajadores. Los aportes del gobierno se limitan a $0.5 \%$ de los salarios. (Véanse, N. Samaniego (2014), El largo camino hacia un seguro de desempleo en México, inédito, Grupo Nuevo Curso de Desarrollo, unAM, México; S. Escobar (2014), El seguro de desempleo en México y la Experiencia Internacional, inédito Grupo Nuevo Curso de Desarrollo, unam, México). 
Con el mismo enfoque de gradualidad, quizá resultase aconsejable crear un gravamen a las transacciones financieras. Aquí se perseguirían no sólo fines recaudatorios o de progresividad impositiva, sino frenar la especulación financiera que está en la raíz de las crisis recientes, incluida la global de 2008.35 En Brasil se implantó exitosamente durante más de una década y también podría dar cabida a acciones más amplias de carácter multilateral. Al respecto, han surgido repetidamente iniciativas, sobre todo en la Unión Europea, pero hasta ahora ha prevalecido la oposición de la banca internacional y la de algunos países donde se concentran los servicios financieros (Estados Unidos, Inglaterra, Japón).

El gravamen a las transacciones financieras podría verse como un paso preliminar antes de poner en consideración intergubernamental la vuelta a los impuestos progresivos directos o al impuesto a la riqueza, sugerido por Piketty con apertura plena a la información de todos los bancos. No se intentaría frenar directamente el patrimonialismo concentrador de las grandes fortunas, sino crear desincentivos a la especulación y a los desórdenes asociados a la volatilidad de los flujos financieros y monetarios entre países. Al mismo tiempo, el impuesto tendería a reforzar la red de normas regulatorias aplicables a las instituciones financieras. Por supuesto, las recaudaciones de impuestos no resolverían de raíz el fondeo de las políticas sociales, pero contribuiría a aliviar restricciones sobre todo al reducir las erogaciones públicas extraordinarias que suelen suscitar las crisis.

Otro paso, moral y políticamente, indisputable consistiría en impulsar al alza los salarios mínimos para iniciar la cadena de ajustes a las remuneraciones rezagadas al trabajo. Por supuesto, las acciones serían de corte nacional para tomar en cuenta las condiciones precisas de cada país. Sin embargo, sería oportuno un mínimo de coordinación internacional a fin de cerrar la brecha entre una capacidad de producción parcialmente ociosa y una demanda mundial insuficiente (véase de nuevo al cuadro 3). 36

35 El llamado Tobin Tax es un impuesto sobre el intercambio de monedas de diferentes países, con una tarifa baja $(0.5 \%$ a $0.1 \%)$, diseñado para atenuar la volatilidad de los tipos de cambio y de los movimientos especulativos asociados. Ese tipo de gravámenes se podría extender a operaciones con acciones, bonos futuros y derivados. La iniciativa ha sido puesta en práctica parcial con distintas modalidades en varios países (Brasil lo estableció entre 1993 y 2007), en Inglaterra hay un gravamen sobre la compra de acciones (British Stamp Duty) y casos análógos se dan en muchos otros países (Polonia, Portugal, Suiza, Hong Kong, China, New York, Singapur). (Véanse, J. John (1978), "A Proposal for International Monetary Reform", Eastern Economic Journal, vol. 4, pp. 153159; M. Cintra (2009), A Modern Tax Technology: the Brazilian Experience with Bank Transaction Tax (1993-2007), University Library Munich, MPRA, Paper núm. 16720, Alemania).

36 El caso de México es singularmente notorio. El salario mínimo en términos reales ha caído $70 \%$ entre 1980 y 2008, quedando por debajo (20\%) de la línea de la pobreza. La participación del trabajo en el producto se redujo más de $31 \%$ en el mismo periodo, siendo el más bajo entre los miembros de la OCDE. (Véanse, Escobar, S. (2014), El salario mínimo y los salarios en México, inédito, Grupo Nuevo Curso de Desarrollo, unAm, México; Samaniego, N. (2014), Desigualdad y Mercado de Trabajo en México, inédito, Grupo Nuevo Curso de Desarrollo, unAm, México. Esquivel, G. (2014) "Salarios mínimos: debate mezquino", El Universal, 15 de agosto, México; The Economist (2014), México's Minium Wage: Stingy by any Measure, 16 de agosto; C. Moreno-Brid (2014), Se me olvidó 
El rezago innegable de las políticas sociales contemporáneas se expresa no sólo en sufrimiento humano y en limitar la participación democrática en los órganos de los gobiernos, sino en alimentar movimientos cada vez más abiertos de desaprobación al orden político vigente que corren paralelos a la desprotección social de muchas regiones y países. La primavera árabe, los indignados de Europa y sus congéneres de Estados Unidos, los repetidos disturbios latinoamericanos, asiáticos o de Medio Oriente, tienen como raíz común la protesta enderezada contra el eficientismo económico que avasalla a la incipiente democracia global y a la de los países con impedimentos a la participación política efectiva de la mayoría de las poblaciones. En rigor, la inalterada alianza conservadora entre gobiernos y elites financieras están detrás de ese estado de cosas y del consiguiente malestar social.

Hay, desde luego, opciones más o menos posibles de formar frentes amplios, coaliciones políticas distintas, aún en ausencia de hechos traumáticos -como la profundización o repetición de la crisis global - que asociaran a gobiernos con corporaciones productivas no financieras, con empresas medianas y pequeñas, con trabajadores, con las clases medias, con los grupos informales y con otros miembros de la sociedad interesados en frenar los excesos de los mercados, en redistribuir ingresos y en devolver poder ordenador a los estados. Sacar de la hibernación a la democracia global y de los países es un imperativo categórico, aún siendo desiderátum utópico mientras subsista el dominio de los paradigmas neoliberales. El cambio llegará tarde o temprano vía la acción humana, al persistir y aún ahondarse las fallas estructurales del mundo, que a la postre obligarán a cambiar los paradigmas de la protección social.

\section{Bibliografia}

Abramovich, V. y C. Curtis (2004), Los Derechos Sociales como Derechos Exigibles, Trotta, Madrid.

Amsden, A. (2001), The Rise of the Rest: Challenges to the West from Late Industrializing Economies, Oxford University Press, N. York.

Banco Mundial (1993), The East Asia Miracle, Oxford University Press, Oxford.

Blinder, A. (1982), Private Pensions and Public Pensions: Theory and Fact, Working Paper núm. 902, NBER, Michigan.

Campos, R. et. al. (2014), Los ingresos altos, la tributación óptima y la recaudación posible, inédito, México. CEPAL (varios números), Panorama Social de América Latina, Santiago de Chile.

Cintra, M. (2009), A Modern Tax Technology: the Brazilian Experience with Bank Transaction Tax (1993-2007),

University Library Munich, MPRA, Paper núm. 16720, Alemania.

Connelly, M. y P. Kennedy (1994), "Must it be the Rest Against the West?", Atlantic Monthly, vol. 274, núm. 6, pp. 61-84.

Cornwell, C. et al. (1998), Pensions and Productivity, Upjohn Institute for Employment and Research, Michigan. Daly, M. et. al. (2012) "Did the Natural Rate of Unemployment Rise?”, Journal of Economic Perspectives, vol.

26, núm. 3, pp. 3-26.

(2010), Okun's Law and the Unemployment Surprise of 2009, Federal Reserve Bank of San Francisco.

que te olvidé: productividad y salarios mínimos en México (incluido en este número de la revista), Economíaunam, México). 
Fraser, D. (1981), The English Poor Law and the Origins of the British Welfare State.

Elsby M. et. al. (2008), Unemployment Dynamics in the OECD, NBER, Working Paper núm. 14617.

Escobar, S. (2014), El seguro de desempleo en México y la Experiencia Internacional, inédito, Grupo Nuevo Curso de Desarrollo, unam, México.

EspingAndersen, G. (1985), Politics against Markets, Princeton University Press, Princeton. (2004), "After the golden Age?, Welfare State Dilemmas in a Global Economy", Welfare States in Transition. Sage Publications LTD.

Evans, E. (1978), Social Policy 1830-1914, Individualism, Collectivism and the Origins of the Welfare State, Routledge and Kegal, Londres.

Gilens, M. (2012) "Affluence and Influence", Economic Inequality and Political Power in America, Princeton University Press, Princeton.

Ham, R. y B. Ramirez (2006), Efectos económicos de los sistemas de pensiones, Colegio de la Frontera, Plaza y Valdés, México.

Hollweg, C. et al. (2014), Sticky Feet, How Labor Market Frictions Shape the Impact of International Trade on Jobs and Wages, The World Bank, Washington.

Ibarra, D. (2006), La Reconfiguración Económica Internacional, unAM, México.

(2007) “Derechos Humanos y Realidades Sociales”, en L. Orcí y V. M. Martínez Bullé, Los Derechos Humanos, Económicos, Sociales y Culturales, Comisión Nacional de los Derechos Humanos, México. (2007) "Limitantes a los servicios nacionales de salud" en Derechos Humanos y Realidades Sociales, unAm, Facultad de Economía, México.

(2012) "Mercado de trabajo y protección social” en la Crisis inacabada, Facultad de Economía, unAm, México.

ILO (2012), Eurozone Job Crisis, Ginebra.

(2012), Statistical Update in the Internal Economy, Ginebra.

(2013), Beyond Macroeconomic Stability, Ginebra. (varios números), Global Employment Trends, Ginebra. (varios números), World of Work Report, Ginebra.

IMF (2007), World Economic Outlook, The Globalization of Labor, Washington.

John, J. (1978) “A Proposal for International Monetary Reform”, Eastern Economic Journal, vol. 4, pp. 153159.

L. y Martínez Bullé, V. M., Los Derechos Humanos, Económicos, Sociales y Culturales, Comisión Nacional de los Derechos Humanos, México.

Mair, P. (2006) “The Hollowing of Western Democracies”, New Left Review 42, pp. 2551.

Moreno-Brid, J.C. (2014), Vecinos distantes: productividad laboral y salarios mínimos reales, inédito, Fundación Friederich Ebert, México.

Neil, B. y J. Frank (2010), US Pension Reform: Lesson from other Countries, Peterson Institute for International Economics, Washington.

Noah, T. (2012), The Great Divergence, Bloomsburg Press, N. York.

Noguera, J. (2001), La renta básica y el principio contributivo, Ariel, Barcelona.

Norris, P. (2011), Democratic Deficit, Cambridge University Press.

Ocampo, J. A. et. al. (2009), Growth and Policy in Developing Countries: a Structuralist Approach, Columbia University Press. 
OECD (2011), Divided we Stand: Why Inequality Keeps Raising, Paris.

(2012), Employment Outlook, Paris.

Offe, C. et. al. (1996), Basic Income Guaranteed by the State, Modernity and the State, The Mit Press, Cambridge, Mass. U.S.A.

оाт-омc (2009), La Globalización y el Empleo Informal de los Países en Desarrollo, Ginebra.

Piketty, T. (2014), Capital in the Twenty First Century, Harvard University Press.

Piketty T. y E. Saez (2003), "Income Inequaliy in the United States”, Quarterly Journal of Economics, 118, núm.

1, pp. 1-39.

Pickett, K. y Wilkinson, R. (2009), The Spirit Level, Allen Lane, Inglaterra.

Pisarello, G., (2007), Los derechos sociales y sus garantías, Trotta, Madrid.

Pisarello, G. y de Cabo, A. (2006), La renta básica como nuevo derecho ciudadano, Trotta, Madrid.

Polanyi, K. (1944), The Great Transformation, Rinehart, Nueva York.

Raventós, D., et al. (2012), "Renta básica ciudadana”, Sin Permiso, México.

Rawls, J. (1997), Teoría de la Justicia, Fondo de Cultura Económica, México.

Samaniego, N. (2014), El largo camino hacia un seguro de desempleo en México, inédito, Grupo Nuevo Curso de Desarrollo, unAm, México.

Schafer A. y W. Streeck (2013), Politics in the Age of Austerity, Polity Press, Inglaterra.

Sen, A. (2006), El valor de la democracia, Viejo Topo, Barcelona.

Stiglitz, J. (2012), The Price of Inequality, WW. Hampton, N. York.

Stiglitz, J. y H. Yasu (2003), Rethinking the East Asia Miracle, Oxford University Press, N. York.

Swenson, P. (2002), Capitalism against Markets": The Making of Labor Markets and Welfare States in the United States and Sweden, Oxford University Press, Oxford.

Titmuss R. (1963), Essays on "The Welfare State", Allen and Unwin, Londres.

Torres, R. (2010), “Incomplete Crisis Reponses”, International Labor Review, vol. 149, núm. 2, pp. 127-137.

Ullman, H. (1981), German Industry and Bismarck's Social System, Croom Helm, Londres.

Webb S. y B. Webb (1910), English Local Government: English Poor Law History, Longmans, Green, Londres. Wood, C. (2002) "Voter Turnout in City Elections”, Urban Affairs Review, núm. 38, pp. 209-231.

Zalewski, D. y Whale C. (2010) "Financialization and Economic Inequality", Journal of Economic Issues, núm. 44 (3), pp. 757777.

Página internet: www.davidibarra.com.mx 